\title{
Relaçōes entre design gráfico e revistas brasileiras de jogos eletrônicos da década de 1990
}

\section{Relationships between graphic design and Brazilian electronic games magazines of the 1990s}

SILVA, Luiz Carlos Teixeira da

Universidade Estadual Paulista - UNESP I luiz@doisdi.com

MORETTO, Joicelaine

Universidade Estadual Paulista - UNESP I joice@doisdi.com

DOMICIANO, Cássia Letícia Carrara

Universidade Estadual Paulista - UNESP I carrara@faac.unesp.br

NAKATA, Milton Koji

Universidade Estadual Paulista - UNESP I milton@faac.unesp.br

\begin{abstract}
Resumo
Esse trabalho propõe levantar informações sobre as revistas brasileiras de games dos anos 90, período que foi marcado pela popularização do uso de computadores, culminando, no design, em criações digitais características. Com uma abordagem qualitativa, a pesquisa exploratóriodescritiva utiliza procedimento bibliográfico no levantamento de dados. Questiona-se aqui alguns aspectos como o foco das editoras, o perfil dos leitores e o projeto gráfico das revistas abordadas. Desse modo, foram apresentados dados sobre cada um desses pontos e uma avaliação sobre as características de quatro revistas brasileiras de games.

\section{Abstract}

This work aims to collect information about the Brazilian games magazines of the 1990s - a decade marked by the popularization of computers, which resulted in specific digital innovations from the design perspective. This exploratory-descriptive research has a qualitative approach, using bibliographic procedures in the data collection. Aspects such as the focus of the publishers, the readers' profile and the graphic design applied to the magazines are questioned here. Thus, we present data on each of the aspects mentioned and we perform an evaluation on the characteristics of four Brazilian games magazines.
\end{abstract}

Palavras-chave: Design gráfico. Design editorial. Revistas. Games.

Keywords: Graphic design. Editorial design. Magazines. Games. 


\section{INTRODUC̣ÃO}

A década de 1990 foi conhecida por diversos acontecimentos marcantes inclusive no Brasil. Os computadores estavam se tornando cada vez mais populares e a Internet se consolidava. Em meados da década, o país passava por uma estabilidade financeira (BOURROUL; FARIA, 2014), permitindo novos negócios e o mercado de jogos eletrônicos voltava a crescer. No design, uma das influências era a Desconstrução'. O público brasileiro conhecia a nova MTV nacional e uma geração era moldada sob influências do vídeo.

Foram também nos anos 90 que surgiram, no Brasil, diversas revistas especializadas em jogos eletrônicos, conhecidos popularmente como games. Essas revistas se tornaram um marco importante no país, pois foram pioneiras como um meio de comunicação adequado que abordasse o universo dos jogos eletrônicos, diante da escassez desse tipo de informação.

Em 2012, o site UOL Jogos iniciou um documentário sobre as revistas de games dos anos 90 contando a história de algumas delas. Nos vídeos, os entrevistados relatam a origem, as dificuldades e como o mercado editorial e dos jogos influenciaram nas trajetórias das revistas. O documentário quase nada dizia sobre projeto editorial e menos ainda sobre design gráfico, mas dava pistas de como as revistas eram tecnicamente produzidas.

Sabe-se que alguns parâmetros são definidos em um projeto editorial no desenvolvimento de uma revista. Tal projeto costuma ser multidisciplinar e procura atingir os objetivos comunicativos e também os comerciais. No processo de criação da identidade de uma revista, é definido também seu projeto gráfico que traduz graficamente o que foi estabelecido no projeto editorial. Pensando na dinâmica da construção e manutenção dessa identidade para a revista, o projeto gráfico ainda pode definir obrigatoriedades e liberdades na construção das páginas.

Com um olhar de design, ao avaliar as características visuais de cada revista pesquisada, é fácil ser conduzido a questionar como seus projetos editoriais e projetos gráficos foram concebidos. Quais valores realmente interessavam para o leitor de uma revista sobre games nos anos 90 ? Tais revistas conseguiam exercer seu papel como produto que transmitia determinada informação e seu valor simbólico parecia ser um fator bastante elevado.

Desse modo, o propósito desse trabalho foi levantar informações sobre as revistas de games dos anos 90 e analisar seus projetos gráficos diante de 
algumas influências da época. Usaram-se como fonte de pesquisa, além dos vídeos já citados, depoimentos cedidos por e-mails em 2016 e 2017 pelos profissionais envolvidos nas produções da época e o acervo pessoal dos autores, contendo inúmeras revistas digitalizadas para leitura, conservação e pesquisa. Assim, pretende-se, além de um importante registro histórico de uma produção em design nacional, questionar alguns aspectos como o foco das editoras, o perfil dos leitores e o projeto gráfico. Tal discussão pode contribuir em futuros projetos editoriais para um público-alvo bastante específico.

Com uma abordagem qualitativa, a pesquisa exploratório-descritiva utiliza procedimento bibliográfico no levantamento de dados. Foram avaliadas as quatro principais revistas brasileiras com foco exclusivo em jogos eletrônicos para consoles. Os títulos escolhidos foram as revistas Ação Games, Gamers, SuperGamePower e VideoGame das editoras Abril, Escala, Nova Cultural e Sigla, respectivamente. A escolha levou em consideração sua popularidade e o tempo de circulação durante a década de 1990.

\section{DESIGN GRÁFICO, REVISTAS E PROJETO EDITORIAL}

Antes de falar especificamente do trabalho realizado nas revistas de games, é pertinente esclarecer conceitos fundamentais sobre design gráfico, revista e projeto editorial. Segundo Samara (2011) as publicações são aplicações extensas de imagens e textos e por isso, concernentes ao design gráfico. O designer pesquisa, organiza e formata tais informações, preocupando-se não apenas com sua forma, mas com o processo de percepção e cognição do leitor.

Uma revista é um produto periódico, impresso ou digital, que normalmente contém uma coleção de conteúdos relacionados, ligados por um projeto editorial e uma identidade gráfica. Ela é fácil de usar e traz grande quantidade de informação, nos dando referências para formação de opiniões. Além disso, é periódica e procura estabelecer uma relação com o leitor, Ihe sendo familiar e íntima, considerando em sua elaboração seus sonhos e anseios (ALI, 2009).

São fundamentais em nossa cultura por meio de sua essência portátil, tátil, repetitiva renovável e relevante. Os métodos atuais de produção permitem que as revistas se mantenham na linha de frente da comunicação moderna, sendo objeto de inspiração para diversos profissionais, inclusive os designers (LESLIE, 2003). É um produto que cria uma afinidade emocional com seu público, por meio de seu conteúdo específico e segmentado. Ainda de acordo com Fátima Ali (2009), as revistas são classificadas em:

- Revistas de consumo, podendo ser de interesse geral, segmentadas por público ou segmentadas por interesse; 
- Revistas Profissionais, direcionadas a classes específicas;

- Revistas de empresas e organizações, usadas para comunicação interna ou com o público consumidor/usuário;

- Suplementos de Jornal, geralmente semanais;

- Zines, revista de baixo custo e tiragem dirigida a "tribos" específicas;

- Revistas digitais, sem papel, mas com grande parte das características editoriais das revistas tradicionais mantidas.

$\mathrm{Na}$ criação de uma revista, parâmetros são estabelecidos por meio de um projeto editorial. São avaliados diversos aspectos com a participação de profissionais de áreas como jornalismo, marketing, design e comunicação. O projeto deve atingir os objetivos comunicativos e também os comerciais. Algumas diretrizes são os objetivos da revista, seu público-alvo, a definição de capa, a linguagem e a organização visual e quantitativa do conteúdo (GUARALDO, 2012).

O projeto editorial se responsabiliza pela identidade da revista visando atingir um grupo específico de leitores. Desse modo, cria-se então um projeto gráfico para tornar visuais as diretrizes estabelecidas, orientando o design gráfico da publicação. O projeto cria uma estrutura que é seguida pelas edições, independente da alteração nas características de seu conteúdo. Para traduzir graficamente uma identidade por meio do que estabeleceu o projeto editorial, o projeto gráfico trabalha com itens como o formato e tipo de papel, tipografia, paleta de cores, capa, tipos diferentes de imagens, ocupação de espaço, grade e até elementos visuais como número das páginas, setas sombras e fios (GUARALDO, 2012).

Desse modo, por meio dos elementos gráficos "o processo de identidade se dá no reconhecimento e na consagração de determinados signos que mais caracterizam um grupo de indivíduos diante do seu uso sistêmico e, principalmente, na sua constância formal." (CONSOLO, 2015). Pensando na dinâmica da construção e manutenção dessa identidade para a revista, o projeto gráfico ainda pode definir obrigatoriedades e liberdades na construção das páginas da revista.

\section{HISTÓRIA DAS REVISTAS DE GAMES}

Como um dos objetos de estudo desse trabalho são revistas brasileiras de consumo, que abordam jogos eletrônicos, é interessante descrever um histórico comparativo entre o mercado de games e o de revistas especializadas nessa área. Os jogos eletrônicos têm origem a partir da década de 1940, com a construção de máquinas que disponibilizavam desafios simples como tiro ao alvo. No final dos anos 70, os jogos eletrônicos alimentados por fichas ou moedas, chamados de arcades ou fliperamas, eram bastante populares em 
suas casas especializadas. Foi nessa época que surgiu a primeira revista focada no assunto, a americana PlayMeter, como um meio de comunicação para suprir uma necessidade crescente de obter informação sobre o mercado de jogos eletrônicos.

Com a evolução dos computadores veio também a redução na dimensão física de alguns aparelhos e foi em 1977 que nasceu o Video Computer System da americana Atari (THE STRONG, 2016). Este aparelho doméstico não foi o primeiro a surgir, mas foi o principal protagonista da denominada primeira geração de consoles, dispositivos domésticos que permitiam operar jogos eletrônicos ligados a um televisor. Diversas empresas começaram a se destacar nesse novo mercado de entretenimento e inúmeros jogos apareciam nas lojas por todo o mundo. No início da década de 1980, sugiram outras revistas sobre games, como a Computer and Video Games do Reino Unido. Em 1983, depois de anos de glória, o mercado de games entrou em colapso, principalmente nos EUA, quando muitas empresas produtoras de jogos faliram.

Nessa época, as empresas japonesas Nintendo e SEGA começaram a se tornar populares e se estabeleceram como líderes de mercado de jogos eletrônicos. A partir de 1984 se iniciou uma nova onda comercial, com os games se tornando novamente populares em todo o mundo e centenas de lançamentos invadindo lojas e locadoras. Ainda nos anos 80, surgiam novas revistas como a japonesa Famitsu e americana Electronic Game Monthly, dois dos maiores títulos focados em jogos eletrônicos que ainda estão em atividade.

O final da década de 1980 até meados da década de 1990 foi um período bastante rico no mercado de games. As empresas produtoras de jogos estavam se beneficiando de avanços tecnológicos com novos consoles sendo lançados e, como de costume, novos games acompanhavam a chegada dos aparelhos no mercado. Foi nessa época que houve um aumento considerado na demanda por informação e que novas revistas sobre games começaram a surgir, inclusive no Brasil.

Quadro 1 - Lançamentos dos principais consoles durante a década de 1980 e 1990, que influenciaram tanto o mercado de games, quanto o editorial.

\begin{tabular}{|c|c|c|c|c|c|c|c|c|c|c|c|c|c|c|c|c|c|c|}
\hline & 1983 & 1984 & 1985 & 1986 & 1987 & 1988 & 1989 & 1990 & 1991 & 1992 & 1993 & 1994 & 1995: & \begin{tabular}{|l|l}
1996 & \\
\end{tabular} & 1997 & 1998 & 1999 & 2000 \\
\hline NES & & & & & & & & & & & & & & & & & & \\
\hline Master System & & & & & & & & & & & & & & & & & & \\
\hline Gameboy & & & & & & & & & & & & & & & & & & \\
\hline Gamegear & & & & & & & & & & & & & & & & & & \\
\hline Mega Drive & & & & & & & & & & & & & & & & & & \\
\hline NeoGeo & & & & & & & & & & & & & & & & & & \\
\hline SNES & & & & & & & & & & & & & & & & & & \\
\hline Sega CD & & & & & & & & & & & & & & & & & & \\
\hline Sega $32 x$ & & & & & & & & & & & & & & & & & & \\
\hline NeoGeo CD & & & & & & & & & & & & & & & & & & \\
\hline $3 \mathrm{DO}$ & & & & & & & & & & & & & & & & & & \\
\hline Saturn & & & & & & & & & & & & & & & & & & \\
\hline Playstation & & & & & & & & & & & & & & & & & & \\
\hline Nintendo 64 & & & & & & & & & & & & & & & & & & \\
\hline Dreamcast & & & & & & & & & & & & & & & & & & \\
\hline NeoGeo Pocket & & & & & & & & & & & & & & & & & & \\
\hline
\end{tabular}

Fonte: Adaptado de Batista e Ulbricht (2006, p. 93) 


\subsection{As Revistas Brasileiras de Games nos Anos 90}

No Brasil, apesar de alguns títulos escassos da década de 1980, a circulação de revistas sobre jogos eletrônicos foi mais intensa nos anos 90 . Nessa época, havia uma grande demanda por informação sobre jogos, que abordasse lançamentos, fabricantes, tutoriais, pontos de locação e venda, assim como qualquer outra informação desse universo. Algumas editoras brasileiras perceberam que o mercado de jogos eletrônicos estava novamente no auge. Desse modo, entendendo a oportunidade, editoras como a Abril, Nova Cultural, Sigla e Escala formaram equipes destinadas à criação de revistas que falassem sobre games.

Abordar assuntos relacionados a jogos eletrônicos não era tarefa fácil nos anos 90, devido à falta de conhecimento adequado dos profissionais de comunicação dentro do Brasil. Roberto Araújo, editor chefe da revista VideoGame, relembra que em 1991, ano de lançamento da revista, havia um desconhecimento de conceitos e personagens do universo dos games, hoje bastante comuns e populares. Ele relata que a revista teria o papel de apresentar seu conteúdo sobre games e ajudar a cunhar termos e a apresentar histórias ao público (PRANDONI; AZEVEDO, 2015d).

Revistas estrangeiras como as americanas GamePro e EGM e a japonesa Famitsu eram as principais fontes de inspiração para as revistas nacionais, principalmente na definição de pauta. Algumas editoras, como a Nova Cultural, conseguiram fechar parcerias com essas revistas estrangeiras, obtendo acesso antecipado às informações como lançamentos e peculiaridades do mercado de jogos eletrônicos.

As editoras procuraram as locadoras de jogos, o principal meio de comércio dessa área, para estabelecer acordos que beneficiariam ambas as partes. A publicidade das locadoras era inserida na revista em troca de material e informação para as matérias. Tais pontos comerciais, frequentados pelo público principal das revistas, eram locais em que algum membro da redação convidava jovens para jogar e colher material informativo. Desse modo, todas as revistas possuíam equipes de jovens jogadores que colaboravam regularmente nas edições e que trabalhavam em ambientes equipados com jogos, consoles e televisores, dentro da editora. Hoje esta prática é comum em grandes empresas de tecnologia, mas para o perfil brasileiro da época, era algo bastante inovador, ainda mais se tratando de um produto editorial.

Inicialmente, para produzir as revistas não se usava praticamente nenhum recurso digital. As imagens ilustrativas usadas na capa e nas páginas eram reproduções das imagens dos jogos fotografadas da tela da TV. Além disso, cada revista possuía alguns colaboradores que criavam ilustrações manualmente, assim como elaboravam a diagramação de parte das edições. 
Posteriormente, a informatização foi se popularizando e se tornou parte do trabalho dentro da redação, com o uso de equipamentos como Apple Machintosh e softwares de editoração como o QuarkXpress e Aldus PageMaker (hoje substituídos pelo Adobe InDesign). Não havia regras rígidas para o design das páginas dessas revistas. Os responsáveis pela editoração e arte tinham certa liberdade de atuação, mas respeitavam diretrizes da editora e a identidade da revista ${ }^{2}$.

O mercado de games pautava o conteúdo das revistas, pois os jogos mais novos e mais famosos eram retratados nas edições. Durante os anos 90 havia bastante conteúdo para abordar devido aos constantes lançamentos de jogos e também de novos e modernos consoles. No entanto, a partir de 1995, houve um período de escassez de novidades e até o final da década poucos lançamentos relevantes apontavam no mercado, principalmente no lançamento de novos consoles. Isso foi um dos motivos que fez com que as revistas nacionais de games entrassem em crise. Para agravar o quadro, a popularização da Internet trouxe um novo modo de comunicação, os web sites especializados em jogos eletrônicos.

As revistas não eram mais a principal fonte de informação e também acabaram se tornando um meio mais lento e custoso de obtenção de notícias sobre games. Com o passar dos anos finais da década de 1990, poucas revistas conseguiram manter seu foco e suprir as exigências das editoras, fazendo com que a maioria encerrasse as atividades até a virada do milênio.

Quadro 2 - Tempo de circulação das principais revistas nacionais sobre games a partir de 1990

\begin{tabular}{|c|c|c|c|c|c|c|c|c|c|c|c|c|c|c|c|c|c|c|c|c|}
\hline & \begin{tabular}{|l|l|}
1990 & 1991 \\
\end{tabular} & 1992 & 1993 & 1994 & 1995 & 1996 & \begin{tabular}{|l|l|}
1997 & 1 \\
1
\end{tabular} & \begin{tabular}{|l|l|l|l|}
1998 & $=$
\end{tabular} & \begin{tabular}{|l|l|l|}
19992 \\
\end{tabular} & 2000 & 2001 & 2002 & 2003 & 2004 & 2005 & 2006 & 2007 & 2008 & 2009 & 2010 \\
\hline Ação Games & & & & & & & & & & & & & & & & & & & & \\
\hline Game \& Video & & & & & & & & & & & & & & & & & & & & \\
\hline Game Boy & & & & & & & & & & & & & & & & & & & & \\
\hline GamePower & & & & & & & & & & & & & & & & & & & & \\
\hline Gamers & & & & & & & & & & & & & & & & & & & & \\
\hline Herói Games & & & & & & & & & & & & & & & & & & & & \\
\hline Jornal Sega Mania & & & & & & & & & & & & & & & & & & & & \\
\hline Supergame & & & & & & & & & & & & & & & & & & & & \\
\hline SuperGamePower & & & & & & & & & & & & & & & & & & & & \\
\hline VideoGame & & & & & & & & & & & & & & & & & & & & \\
\hline
\end{tabular}

Fonte: Dos autores.

Atualmente, algumas revistas brasileiras continuam em circulação no país, como a Playstation, criada em 1998 com conteúdo exclusivo sobre a plataforma da empresa Sony, a Entertainment Game World criada em 2002 que foca em lançamentos gerais e a WarpZone iniciada em 2015, que explora os jogos mais antigos e clássicos dos anos 80 e 90. (REVISTA EGW, 2016; REVISTA PLAYSTATION, 2016; REVISTA WARPZONE, 2016). 


\title{
3.2 Identidade e Design Gráfico nas Revistas Brasileiras de Games na Década de 90
}

Os títulos nacionais que este trabalho aborda fazem parte da cultura dos anos 90 e suas diversas influências. Tais revistas se originaram em um período onde uma nova e promissora geração de produtos de entretenimento nascia. Isso indicava boas oportunidades comerciais, assim como criava um novo grupo de leitores com anseios específicos. Além da cultura gamer, a década de 1990 foi marcada por mudanças e inovações em diversas áreas, com revoluções artísticas e tecnológicas influenciando a produção gráfica e editorial. A disseminação do uso dos computadores pessoais e a popularização da Internet revolucionaria o modo de produzir e consumir informação durante os anos 90. O chamado "design pós-moderno" pelas influências das ideias desconstrutivistas se mesclavam à era digital em um caos controlado. Como explica Heller e Vienne (2012):

\begin{abstract}
No final da década de 1980, nos estados Unidos, os educadores de design gráfico adotaram as noções de desconstrução, defendidas pelo filosofo francês Jacques Derrida, como uma ferramenta crítica para reinventar a comunicação visual. Coincidindo com o advento da era digital, a tendência construtivista desafiava os padrões aceitos de legibilidade e transformava peças gráficas em cifras tipográficas empolgantes.
\end{abstract}

Tais influências chegavam ao Brasil ao longo dos anos noventa por meio de publicações e toda uma cultura gráfica americana.

Figura 1 - Alguns dos acontecimentos influenciadores da década de 1990.

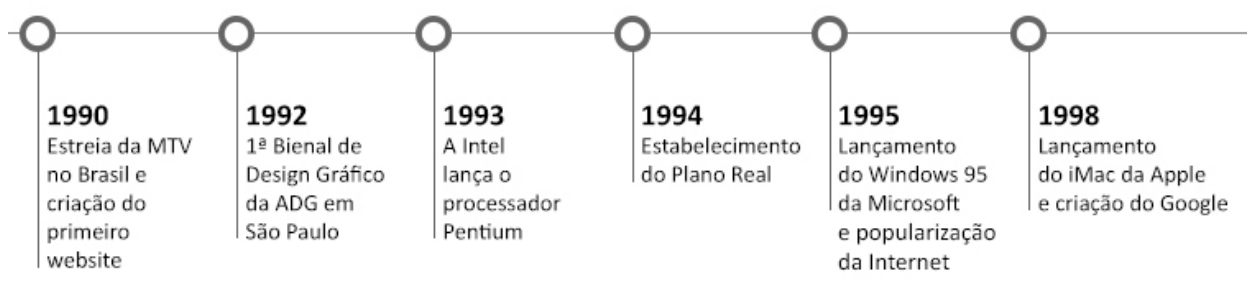

Fonte: Dos autores.

Nesse cenário nasceram as revistas aqui pesquisadas, uma publicação de consumo, segmentada por interesse, usando-se a classificação de Fátima Ali (2009). Tais revistas especializadas em jogos eletrônicos possuem diversas seções e conteúdos distintos, mas relacionados. Assim como é comum encontrar na maioria das revistas, cada seção possui uma característica visual própria, assim como cada revista possui seu próprio projeto editorial e gráfico. Nas revistas nos anos 90 , com exceção das páginas com publicidade 
direcionada que muitas vezes faziam parte do universo dos games, tais seções e conteúdos normalmente eram:

- Matérias sobre jogos: divididos por fabricante, console e/ou estilo;

- Lançamentos de consoles e jogos;

- Dicas e tutoriais: facilitavam os jogadores a realizar tarefas nos jogos;

- Seção de cartas e desenhos dos leitores;

- $\quad$ Entrevistas com personalidades: com pessoas da área ou fora dela, mas envolvia alguma atividade com os games;

- Classificados: venda e troca de jogos e consoles;

- $\quad$ Outras notícias relevantes para a área: como filmes e quadrinhos.

Cada seção tinha sua própria característica e seguia um padrão de projeto gráfico que fazia com que o leitor identificasse com mais rapidez o tipo de conteúdo da página. De acordo com Cadwell e Zapaterra (2014), os designers podem optar por não seguir um formato que caracterize cada seção, mas devem entender que se o fizer, precisam tomar cuidados com o fluxo de navegação e reconhecimento pelos leitores. Nessas revistas a grade, ou grid, e a distribuição do conteúdo pareciam ser conduzidas pelo que a página deveria comportar em determinada edição, além das diretrizes do projeto gráfico. Sobre o grid, Samara (2007) diz que: "Para alguns designers gráficos, ele é parte incontestável do processo de trabalho, oferecendo precisão, ordem e clareza. Para outros, é símbolo da opressão estética da velha guarda, prisão sufocante que atrapalha a busca de expressão."

São características marcantes as construções gráficas destinadas a uma identidade que agradasse ao público jovem das revistas. O grid, que poderia restringir alguns valores do projeto editorial, era algo mutável e não oferecia inibição na concepção das páginas, desde que elas apresentassem o conteúdo de modo adequado. Cada uma das revistas pesquisadas nesse trabalho possuía seu próprio projeto gráfico e, na maioria dos casos, sabia construir seu conteúdo e criar uma identidade distinta.

A revista Ação Games, da Editora Abril, teve uma trajetória de sucesso durante toda a década de 90 . Ela se tornou, inclusive, referência em assuntos sobre jogos eletrônicos pelo público, provavelmente por seu pioneirismo diante seus concorrentes diretos e pelo seu nome marcante. Segundo Paulo Montoia, editor da revista, a marca Ação Games era usada até mesmo de modo ilegal por produtores de cartuchos de jogos pirata com a intenção de dar relevância comercial (PRANDONI; AZEVEDO, 2015a). 
Figura 2 - Capas da Ação Games com a evolução de seu logotipo durante a década de 1990
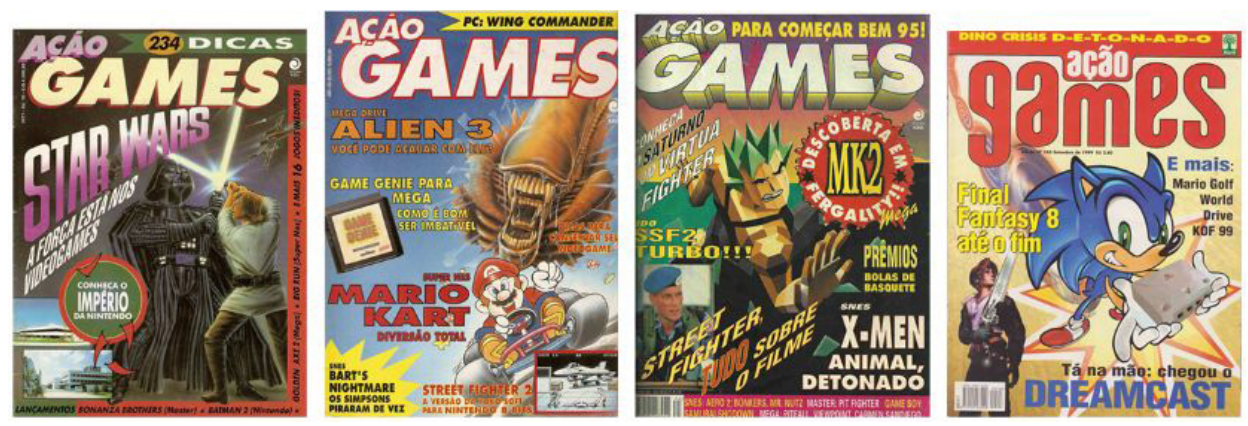

Fonte: Acervo pessoal dos autores

(Ação Games n. 10, 1992; n. 20, 1992; n. 74, 1995; n. 143, 1999).

Consolo (2015) afirma que "quanto mais relevância e ressonância no processo cognitivo, maior a aderência e a permanência do uso desse sinal como signo visual identificador". Destacam-se no projeto gráfico dessas revistas vários elementos que pertencem ao repertório cultural do grupo social que a revista destina. Mesmo com a evolução e alterações no projeto gráfico durante os anos da revista, havia uma constância formal no uso sistêmico desses elementos, como observado no exemplo da figura 3.

Figura 3 - Detalhes de elementos gráficos da revista SuperGamePower com tipografias e cores para diferenciar títulos e consoles

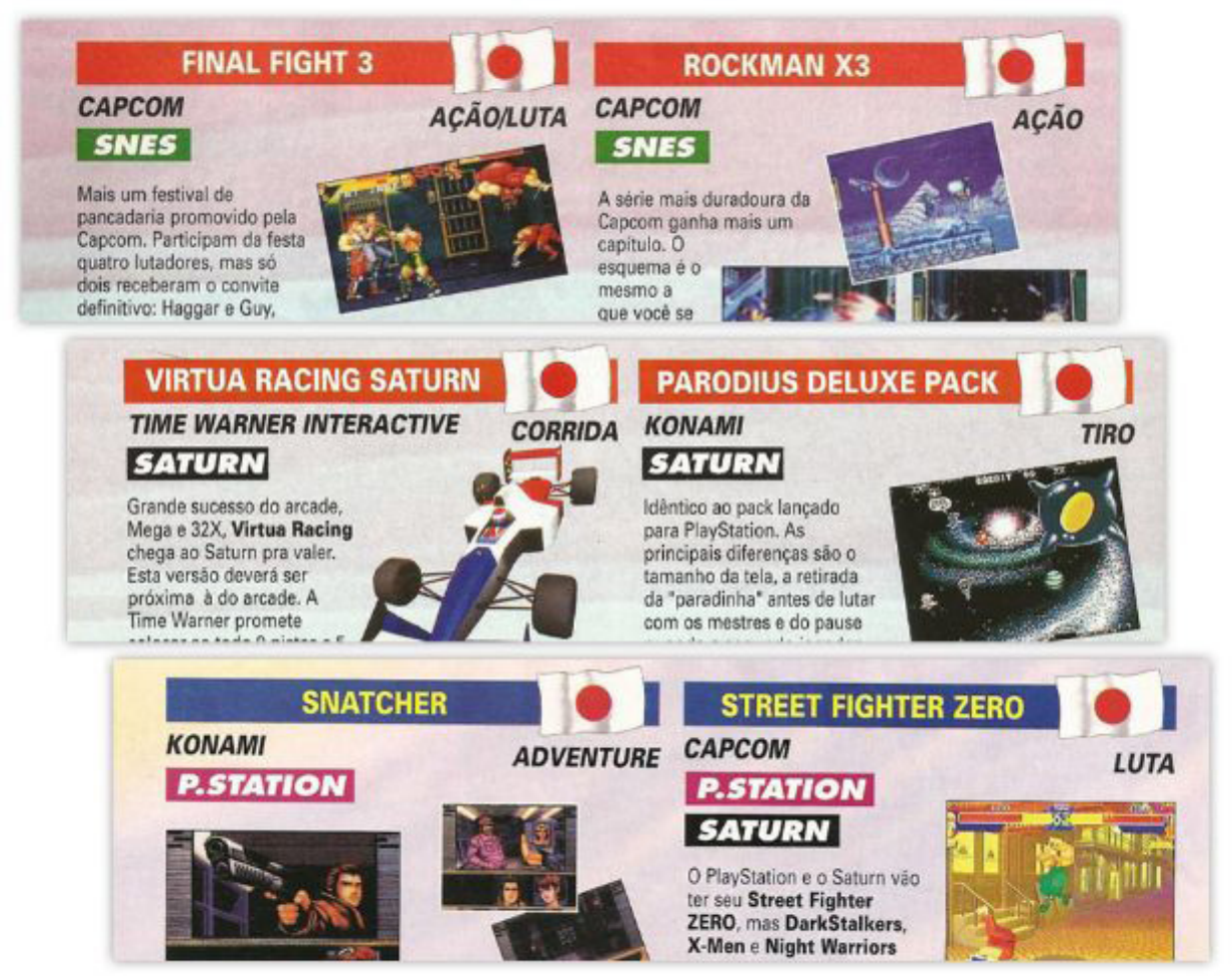

Fonte: Acervo dos autores

(Edições n. 18, 1995, p. 15; n. 13, 1995, p. 18; n. 20, 1995, p. 18). 
Ao analisar o design das páginas dessas revistas, alguns desses projetos editoriais parecem até serem inspirados pelas já citadas influências do design pós-moderno dos anos 90, como é visto em trabalhos do americano David Carson e seu estilo "grunge" (HEITLINGER, 2006). No entanto, essas revistas pareciam apresentar experimentação intuitiva, em uma busca constante da construção de sua própria identidade, criando layouts de página com base no design gráfico dos games. Essas adaptações também eram resultado do trabalho em busca e retenção de leitores, diante das mudanças do mercado editorial e da cultura dos games que estavam acontecendo na década de 90. É possível perceber em muitas páginas a influência dos programas de edição gráfica que permitiam o uso, algumas vezes caótico, de tipografias diferenciadas, "sujeira" proposital e efeitos característicos de tridimensionalidade e distorção.

Figura 4 - Elementos gráficos e efeitos característicos da manipulação digital
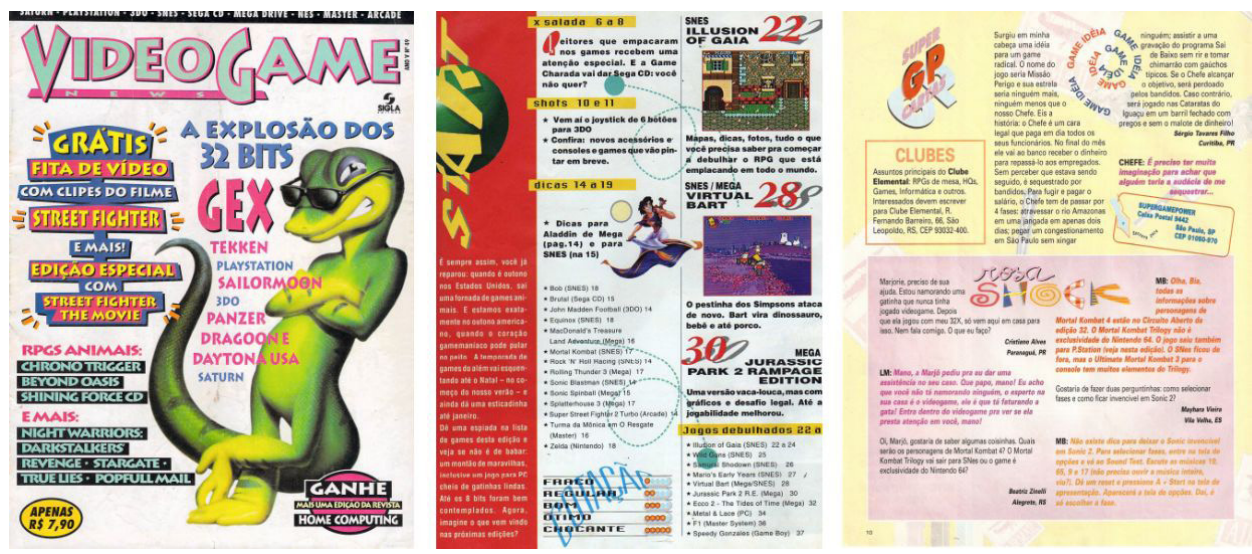

Fonte: Acervo dos autores (Capa da VideoGame n. 49, 1995; índice da Ação Games n. 70, 1994; SuperGamePower n. 33, 1996, p. 10).

A revista VideoGame, da editora Sigla, teve uma trajetória peculiar, sendo uma das primeiras publicações dos anos 90 e que em menos de seis anos encerraria sua circulação. De acordo com Mario Fittipaldi, ex-editor da revista, havia a preocupação com o design gráfico e como ele facilitaria a transmissão de informações aos leitores. Uma das diretrizes mais marcantes que o projeto gráfico estabelecia era que cada console seria representado por uma cor diferente ${ }^{3}$. Nos primeiros anos da revista é possível perceber que essa regra se aplicava na cor de fundo das páginas. Posteriormente, o projeto gráfico foi evoluindo, mas continuou relacionando cores para diferenciar os consoles. 
Figura 5 - Cores de fundo diferentes para representar e diferenciar cada um dos consoles apresentados pela revista
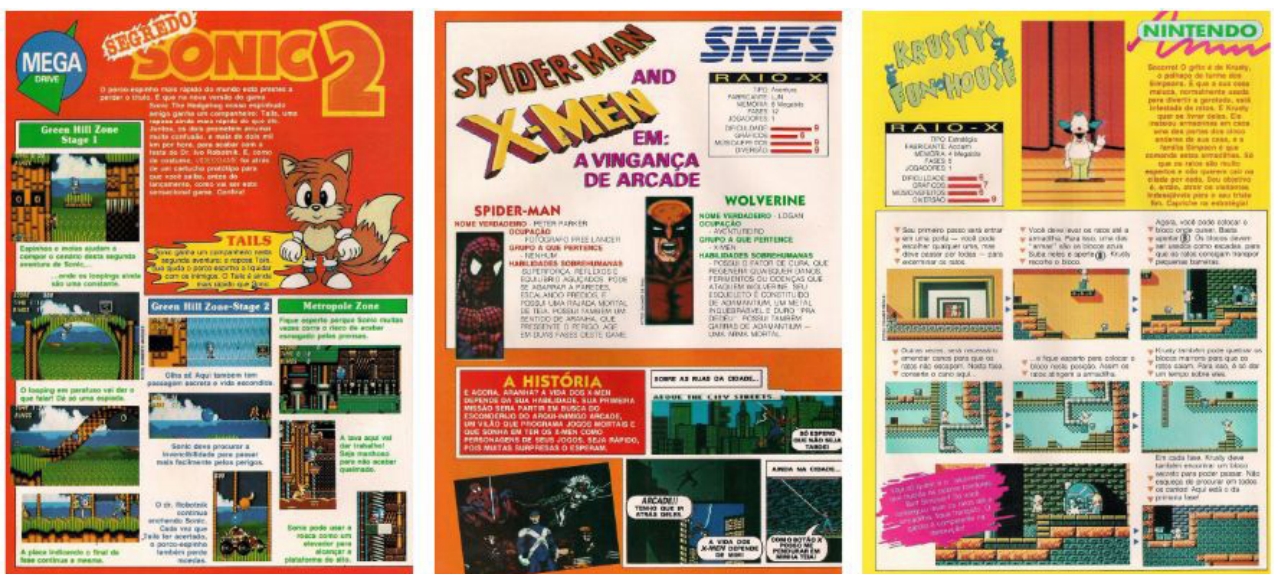

Fonte: Acervo dos autores (VideoGame n. 20, 1992, p. 22, 34, 40).

Segundo Roberto Araújo, ex-redator-chefe da VideoGame, a preocupação com o público jovem também direcionava a arte da revista, que procurava uma linguagem mais descontraída. A contratação de um ilustrador culminou na criação de um personagem recorrente nas páginas da revista, que viria a se tornar sua mascote. Tal personagem se tornou parte da identidade do periódico, ilustrando matérias e auxiliando na comunicação com o público (PRANDONI; AZEVEDO, 2015a).

Figura 6 - O personagem Lig, criação do ilustrador Alexandre Ono, se tornou mascote da VideoGame, ilustrando matérias, avaliações e outras seções da revista.
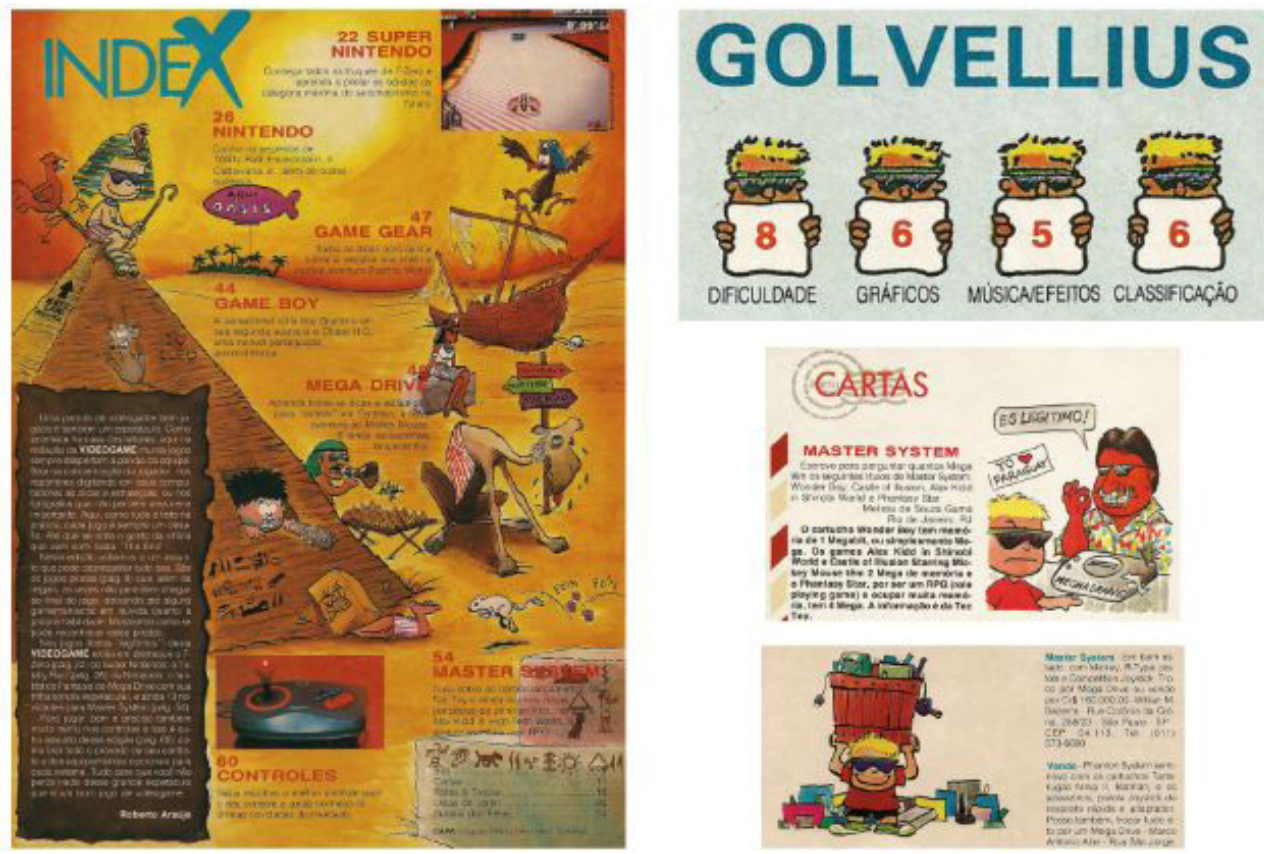

Fonte: Acervo dos autores (Índice da edição n. 8 e imagens das edições n. 8, 1991, p. 19; n. 11, 1992, p. 16, 43). 
Nas revistas pesquisadas havia colaboradores e profissionais da área do design que trabalhavam com as atividades relacionadas ao projeto gráfico. Quando o trabalho ainda era analógico, normalmente era algum departamento de arte das editoras que fazia a maior parte do trabalho gráfico. Com o advento e popularização dos computadores e recursos digitais, o trabalho foi facilitado e realizado por menos colaboradores. No caso da revista VideoGame, por exemplo, havia um designer que coordenava um trabalho feito por artistas, arte-finalistas e operadores de edição eletrônica. Em um determinado momento, a revista passou a ser editada por um único designer ${ }^{4}$.

A revista Gamers é, no entanto, um exemplo de publicação que carecia mais de cuidados em seu projeto gráfico. Havia dois pontos que caracterizaram seu modo de fazer a revista sendo que o primeiro é o fato de que não havia profissionais especializados exercendo as funções principais de editoração. Em 1994, a revista nasceu de uma parceria entre a editora Escala e a ProGames, a maior locadora brasileira de jogos na época. A editora ditava as principais regras e contava com a participação da equipe da ProGames e de colaboradores não-especialistas para escrever, ilustrar, diagramar e editorar (PRANDONI; AZEVEDO, 2015b).

Mesmo na tentativa de estabelecer um projeto gráfico adequado, este era altamente aleatório durante suas primeiras edições. O próprio logotipo da revista não havia se estabelecido até a sexta edição e quando o fez, sofreu alterações drásticas durante sua circulação por mais cinco vezes. A qualidade das imagens costumava ser boa, mas havia problemas na diagramação e na elaboração de um layout que respeitasse a boa leitura do texto, resultado do segundo fator que era a decisão da revista em criar matérias com muitos detalhes sobre o mesmo assunto. Isso muitas vezes criava um acúmulo de informações em uma mesma página, principalmente com texto.

Figura 7 - Exemplos de páginas da revista Gamers em que o layout e a questionável escolha de elementos gráficos não resultavam em um design agradável ao leitor
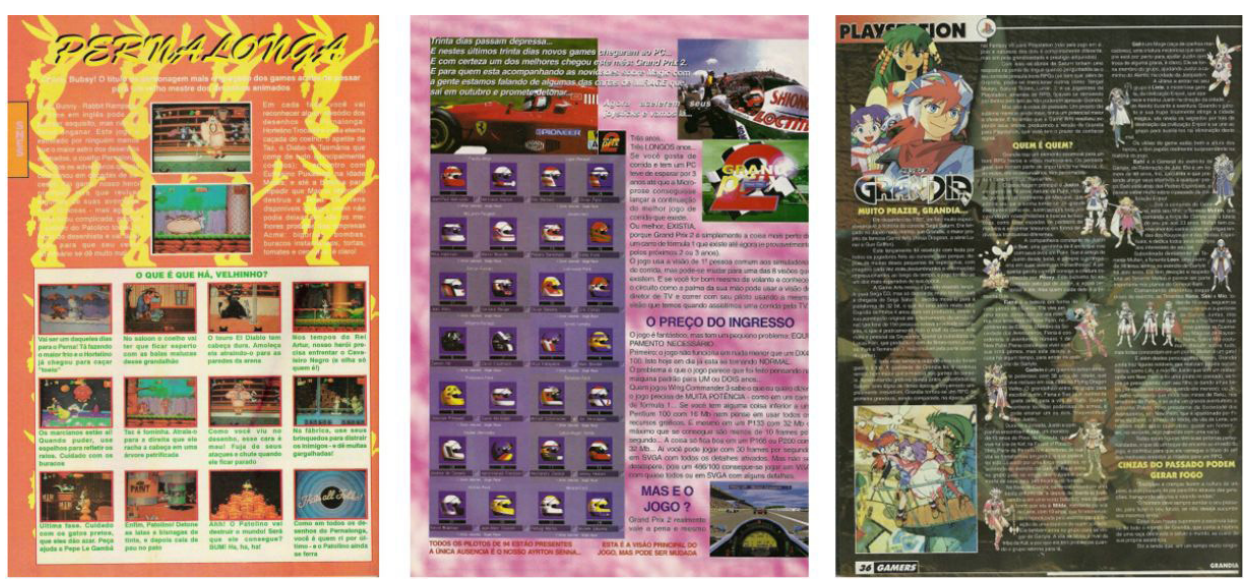

Fonte: Acervo dos autores (Gamers n. 1, 1994, p. 14; n. 12, 1995, p. 48; n. 42, 1999, p. 24).

4 Segundo depoimento cedido por meio de e-mail por ex-funcionário da revista VideoGame em janeiro de 2017. 
Para compensar os pontos negativos do projeto gráfico, os pontos fortes da Gamers eram o humor e o nível das informações sobre jogos. O artista Marcelo Cassaro fez parte da equipe da revista por um curto período, exercendo o papel de ilustrador e diagramador. Mas sua contribuição mais notável foi a criação do personagem Capitão Ninja, que serviria por várias edições como a cara da Gamers. O personagem era recorrente, sendo usado como porta-voz da revista e ainda possuía uma humorística história em quadrinhos no final de algumas edições, onde contracenava com personagens de diversos jogos e outras mídias. Tal criação, aliada com o nível de detalhes das resenhas sobre jogos, fez com que a Gamers restringisse seu público para um tipo de leitor que era menos preocupado com o design da revista e mais interessado em informações sobre seus jogos favoritos em uma revista com um aspecto mais descontraído.

$\mathrm{Na}$ análise das revistas é importante destacar que as imagens comunicam, mas seu aspecto visual pode interferir negativamente na mediação da informação. A ausência de um designer na equipe tem impacto no modo como a mensagem é transmitida. O design se preocupa com a qualidade estética e formal, tendo cuidado em atender as necessidades cognitivas do usuário, planejando a recepção e interpretação da informação oferecida (BONSIEPE, 2011). Mesmo um jogo eletrônico sendo um produto em que o design é crucial em sua concepção, as revistas de games nem sempre utilizavam conscientemente o design. Algumas práticas interferiam na funcionalidade da revista, com o uso inadequado de elementos gráficos. No entanto, essas publicações tiveram sucesso ao levar conteúdo a um público carente por informação. A maioria dos títulos sabia o valor do projeto editorial e do projeto gráfico, pois de uma forma ou outra acabavam por utilizar seus recursos como ferramenta para envolver e fidelizar os leitores.

\section{CONSIDERAC̣ÕES FINAIS}

Diante do exposto, ficou evidenciado que as revistas sobre games dos anos 90 possuíam um apelo emocional bastante elevado - estratégias hoje estudadas inclusive pelo Design Emocional ${ }^{5}$ - utilizando-se da identidade dos jogos eletrônicos como agregador de valor e inspiração gráfica, mesmo que os níveis de funcionalidade e estética fossem baixos em alguns casos. Além disso, garantiam um vínculo com o leitor por meio de estratégias cativantes como a elaboração de personagens e o uso de uma linguagem gráfica e verbal diferenciada, fazendo com que ele se sentisse pertencente a um grupo.

5 Tem o objetivo de despertar emoções nos usuários, mesclando conceitos como o visceral, o comportamental e o reflexivo (NORMAN, 2008). 
A "tribo" que essas revistas focavam eram jogadores de games e entusiastas. Esse público, normalmente jovem, tinha as revistas como o principal meio de obter informação sobre jogos e também como forma de expressão, devido às seções específicas que cada revista possuía, como a de cartas e desenhos de leitores. É importante salientar que apesar dos anseios desse grupo, no Brasil, ele ainda estava sendo formatado durante a década de 1990. Tais leitores se caracterizavam amadores no assunto, comparados à geração que os seguiria. Como não havia comparativos nacionais, acreditase, pelo histórico e depoimentos colhidos, que o público leitor dos anos 90 se sentia satisfeito com as revistas.

Ainda, pode-se dizer que tais revistas foram influenciadas diretamente por mudanças culturais e comerciais. Afinal, o surgimento delas na década de 1990 ilustra um momento de necessidade sendo suprida por meio de um produto editorial, assim como sua decadência, sofrendo com o surgimento de novos meios e com a escassez de informação. Por fim, no período estudado, foi constatado que os profissionais do design tiveram uma participação mínima na concepção dessas revistas e em suas edições.

\section{REFERÊNCIAS}

ALI, Fatima. A arte de editar revistas. São Paulo: Companhia Editora Nacional, 2009.

BOMENY, Maria H. W. O panorama do design gráfico contemporâneo: a construção, a desconstrução e a nova ordem. 2009. 204 p. Tese (Doutorado em Arquitetura e Urbanismo) - Faculdade de Arquitetura e Urbanismo de São Paulo, 2009.

BONSIEPE, Gui. Design cultura e sociedade. São Paulo: Blucher, 2011. BOURROUL, Marcela; FARIA, Michelle. 20 anos do plano real. Época, São Paulo, 2014. Negócios. Disponível em: <http://20anosdoreal.epocanegocios. globo.com/>. Acesso em: 29 out. 2017.

CADWELL, Cath; ZAPATERRA, Yolanda. Design editorial. São Paulo: Gustavo Gili, 2014.

CONSOLO, Cecília. Marcas: design estratégico. Do símbolo à gestão da identidade corporativa. São Paulo: Blucher, 2015.

GUARALDO, Laís. A expressão gráfica nos projetos editoriais. Educação Gráfica, Baurú, v. 16, n. 1, 2012.

HEITLINGER, Paulo. Tipografia: origens, formas e uso das letras. Lisboa:

Dinalivros, 2006.

HELLER, Steven; VIENNE, Veronique. 100 ideas that changed graphic design. Laurence: Laurence King Publishing, 2012. 
LESLIE, Jeremy. Novo design de revistas. Barcelona: Gustavo Gili, 2003.

NORMAN, Donald A. Design emocional. Rio de Janeiro: Rocco, 2008.

PRANDONI, Claudio; AZEVEDO, Théo. História das revistas de videogame: ação games. 2015a. Disponível em: <https://www.youtube.com/ watch?v=zkodO_O_iEl>. Acesso em: 12 out. 2016.

PRANDONI, Claudio; AZEVEDO, Théo. História das revistas de videogame: gamers. 2015b. Disponível em: <https://www.youtube.com/ watch?v=bFzq8jtHDQE $>$. Acesso em: 12 out. 2016.

PRANDONI, Claudio; AZEVEDO, Théo. História das revistas de videogame: super game power. 2015c. Disponível em: <https://www.youtube.com/ watch?v=zKJM8Qc8kDc>. Acesso em 12 de outubro de 2016.

PRANDONI, Claudio; AZEVEDO, Théo. História das revistas de videogame: Video game. 2015d. Disponível em: <https://www.youtube.com/ watch?v=uyZPD3M8kWA>. Acesso em: 12 out. 2016.

REVISTA EGW. São Paulo: Tambor. Disponível em: <http://egw.com.br/>. Acesso em: 9 dez. 2016.

REVISTA PLAYSTATION. São Paulo. Disponível em: <http://www.europanet. com.br/site/index.php?cat_id=67>. Acesso em: 9 dez. 2016.

REVISTA WARPZONE. São Paulo. Disponível em: <http://warpzone.me/>. Acesso em: 9 dez. 2016.

SAMARA, Timothy. Grid: construção e desconstrução. São Paulo: Cosac Naify, 2007.

SAMARA, Timothy. Guia de design editorial. Porto Alegue: Bookman, 2011.

THE STRONG. National Museum of Play. Museum of play. Disponível em: <http://www.museumofplay.org/about/icheg/video-game-history/timeline>. Acesso em: 15 out. 2016. 